Revista Oficial del Poder Judicial

ÓRGANO DE INVESTIGACIÓN DE LA CORTE SUPREMA DE JUSTICIA DE LA REPÚBLICA DEL PERÚ

Vol. 10, n. 12 , julio-diciembre, 2019, 131-148

ISSN versión impresa: 1997-6682

ISSN versión electrónica: 2663-9130

DOI: https://doi.org/10.35292/ropj.u10i12.27

\title{
La prueba indiciaria. Análisis fenomenológico de la valoración de la prueba indiciaria en los delitos de corrupción de funcionarios
}

Circumstantial evidence. Phenomenological analysis of the value of the circumstantial evidence in crimes of corruption of officials

\author{
0 \\ ELIZABETH HILDA QUISPE MAMANI \\ Corte Superior de Justicia de Ica \\ (Ica, Perú) \\ Contacto: equispem@pj.gob.pe \\ https://orcid.org/0000-0001-8219-8011
}

\section{RESUMEN}

El presente aporte formula reflexiones sobre lo que debería significar una correcta valoración de la prueba indiciaria cuando de juzgar delitos de corrupción de funcionarios se trata; y de cuáles deberían ser las directrices y lineamientos que deben observar los operadores de justicia.

Palabras clave: prueba indiciaria, corrupción de funcionarios. 


\section{ABSTRACT}

This article reflects on what the proper valuation of the circumstantial evidence should signify when judging crimes of corruption of officials and which guidelines should be observed by the justice operators.

Key words: circumstantial evidence, corruption of officials.

Recibido: 07/05/19 Aceptado: 31/10/19

El primer signo de la corrupción en una sociedad que todavía está viva es "el fin justifica los medios». Georges Bernanos

La corrupción va de la mano del poder. ¿Habrá manera de separarlos?

LORD ACTON

\section{A MANERA DE INTRODUCCIÓN}

En los últimos tiempos, el tema en análisis está remeciendo los cimientos más importantes del sistema judicial peruano, pues es bastante conocido que diversos pronunciamientos por la presunta comisión de delitos de corrupción de funcionarios han dado lugar a una serie de acontecimientos singulares que vienen marcando hitos trascendentales en la historia judicial peruana. No debemos perder de vista que «los jueces están comprometidos no solo para saber gobernarse bien, sino también para propiciar cambios sistémicos sustanciales con miras a su desarrollo institucional» (Salas 2012: 314).

Cabe destacar la importancia de la prueba en la averiguación de los hechos investigados, pues esta se erige como la piedra angular 
de todo el razonamiento jurídico; por ende, deviene en un aspecto fundamental para la aplicación del derecho porque a través de ella se logra la conexión de los hechos con la realidad. Por ello la valoración de la prueba es fundamental, más aún cuando se trata de una "prueba indiciaria». La naturaleza intrínseca de los delitos de corrupción de funcionarios, de por sí, implica el quiebre de la imparcialidad del funcionario público en el ejercicio de sus labores, toda vez que el cargo conferido o actividad encomendada le sugiere al servidor el deber de lealtad que le alcanza para con el Estado. No debemos dejar de lado el quiebre de la confianza depositada por la sociedad en los funcionarios que eligen en busca de una nación cada día mejor.

Sabido es que países como Brasil están soportando las consecuencias de una sociedad que lucha día a día para enfrentar el fenómeno de la corrupción incrustada en todos los estratos sociales, con mayor énfasis en las actividades que le han sido encomendadas a los funcionarios y servidores elegidos por voluntad popular. Esta situación no se aleja mucho de nuestra realidad, pues es harto conocido que la lucha frontal adoptada por nuestro sistema de justicia contra la corrupción ha levantado voces de protesta de opiniones sociales divididas, que cuestionan las decisiones adoptadas por los jueces, quienes, en su gran mayoría, valiéndose del aporte probatorio de las pruebas indiciarias - no directas-, han emitido pronunciamientos de trascendencia nacional e internacional al resolver cuestiones relacionadas con medidas coercitivas de carácter personal.

Hace algunos meses Transparencia Internacional presentó la última versión de su Índice de Percepción de la Corrupción (IPC), $\mathrm{y}$ sus conclusiones nos dejaron un gusto amargo. El retroceso fue notorio en once países: México registró la mayor caída y Venezuela se consolidó como uno de los países más corruptos del mundo. Recordemos que, últimamente, han surgido diversas denuncias de corrupción vinculadas al caso Odebrecht, que han tenido serias 
repercusiones en Brasil así como en nuestro país. Hasta el momento ya se han iniciado investigaciones en Panamá, Venezuela, Colombia y hasta Chile, considerado uno de los países menos corruptos de América Latina. Todos estos países han dejado entrever que tienen algo que esconder. En el Perú, las consecuencias de la corrupción - hasta el momento - se han traducido en la mayor organización criminal que ha involucrado a grandes personajes de la política, pues nunca antes habían sido acusadas tantas personas cercanas al poder en tantos países de Sudamérica al mismo tiempo (Perú21 12 de junio de 2017).

Luego de estas breves reflexiones sobre la importancia de la prueba indiciaria en los delitos de corrupción de funcionarios, pasaremos a analizar el tema que nos convoca. Adelantamos que nuestro análisis no se avoca únicamente a casos determinados de polémica actual, dada la condición de las personas comprendidas como investigados, lo que se pretende es dar luces a los operadores de justicia sobre la importancia que deben otorgar a la prueba indiciaria cuando se trate de dar valor probatorio a esta.

\section{LA CORRUPCIÓN EN LOS SISTEMAS JUDICIALES}

El 9 de diciembre de 2015 se celebró, en el Perú y en todos los países miembros de las Naciones Unidas, el Día Internacional contra la Corrupción. Esto nos demuestra el real interés por combatir este flagelo humano y los retos que están asumiendo los Estados partes a fin de promover y fortalecer las medidas tendientes a prevenir y combatir de manera eficiente y eficaz el fenómeno de la corrupción, que hoy en día se ha intensificado en las sociedades modernas y viene adoptando nuevas facetas para su realización.

En el caso de Brasil:

Un estudio de Transparencia Internacional (TI) señala que la corrupción es un cáncer del mundo que data desde hace 3,500 años. Brasil, cuyo sistema de gobierno no es autoritario políticamente 
hablando, pero sí ceñido de corrupción desde el gobierno de Luiz lnácio Lula da Silva, pues veinticinco personas fueron condenadas en 2012 por usar fondos públicos para conseguir respaldo político. Actualmente, la mandataria brasileña Dilma Rouseff, está siendo investigada por temas de corrupción, más de un millón de personas han protestado en las calles demandando su renuncia por el caso de Petrobras (González 19 de marzo de 2016).

Pero es necesario precisar que la corrupción no solo está presente en América Latina, se encuentra, asimismo, en otros países del mundo. En Corea del Sur, en el año 1995 murieron quinientas dos personas al desplomarse un edificio mal construido. Se descubrió que funcionarios edilicios fueron sobornados por los constructores a fin de que dejaran pasar la construcción en la que utilizaron materiales de baja calidad. Mientras que en el año 2013, más de veintidós mil funcionarios en Sudáfrica fueron acusados de malversación. En Guatemala también se han asomado los tentáculos de la corrupción. Se sindicó a la exvicepresidenta Roxana Baldetti de comandar la trama del ente regulador de los impuestos. En este caso también estaría implicado el expresidente Otto Pérez Molina. Ambos han sido procesados penalmente, y lo más resaltante de la situación es que no finalizaron su período de gobierno, pues el parlamento guatemalteco los destituyó por sus presuntos vínculos con la corrupción. Nicaragua tiene, igualmente, un alto índice de corrupción de ex funcionarios públicos que causaron perjuicio al Estado, sin embargo, ninguno está tras las rejas aún.

Mientras que en el Perú, el Instituto Nacional de Estadística e Informática (INEI) señaló que la corrupción desplazó a la delincuencia como el principal problema que afecta al país, según la última Encuesta Nacional de Hogares (ENAHO) realizada entre noviembre de 2016 y abril de 2017 (Perú21 12 de junio de 2017). Altas autoridades $\mathrm{y}$ funcionarios públicos, alcaldes $\mathrm{y}$ exalcaldes provinciales $\mathrm{y}$ 
distritales del país están siendo investigados y algunos ya fueron sentenciados por diversos delitos de corrupción; en su gran mayoría estos llegaron a tejer sofisticadas redes para cometer delitos contra el Estado. A manera de referencia tenemos el caso Carlos Renato Moreno Chacón ${ }^{1}$ (negociación incompatible), el caso fiscal Víctor Rosell Espino $^{2}$ (cohecho pasivo específico), el caso Miguel Chehade (cohecho activo genérico), entre otros.

\section{LA VALIDACIÓN DE LA PRUEBA INDICIARIA EN LOS DELITOS DE CORRUPCIÓN DE FUNCIONARIOS}

\subsection{La prueba indiciaria}

Para analizar la prueba indiciaria, es preciso definir en primer lugar el concepto de esta. Conocida también como prueba indirecta, es aquel elemento probatorio que permite dar por acreditados en un proceso judicial hechos sobre los que no existe una prueba directa, pero que a partir de estimar probados otros hechos relacionados con los que se pretende probar, cabe deducir razonadamente la certeza o acreditación de estos últimos.

Veamos algunas otras definiciones sobre la prueba indiciaria:

San Martín Castro dice que por prueba indiciaria se debe entender aquella que se dirige a demostrar la certeza de unos hechos (indicios) que no son constitutivos del delito objeto de acusación, pero de los que, a través de la lógica y de las reglas de la experiencia, pueden inferirse los hechos delictivos y la participación del acusado; señala, además, que ha de motivarse en función de un nexo causal

1 Exp. n. ${ }^{\circ}$ 00092-2011-6-1826-JR-PE-01, sentencia de fecha 10 de junio de 2013, expedida por la Sala de Apelaciones de la Corte Superior de Justicia de Lima (D. D. Susana Castañeda Otsu).

2 Exp. n. ${ }^{\circ}$ 0003-2013-6-1826-JR-PE-0, sentencia de fecha 17 de diciembre de 2014, expedida por la Sala Penal Especial de la Corte Superior de Justicia de Lima (D. D. Susana Castañeda Otsu). 
y coherente entre los hechos probados - indicios- y el que se trate de probar - delito.

Por su parte, Mixán Mass conceptúa la prueba indiciaria como una actividad probatoria de naturaleza necesariamente discursiva e indirecta, cuya fuente es un dato comprobado, y se concreta en la obtención del argumento probatorio mediante una inferencia correcta.

Cabanillas Barrantes dice que la prueba de indicios está basada en todo hecho cierto y conocido que lleva, merced a un razonamiento inductivo, a la determinación de un hecho desconocido, dando por resultado un juicio sintético, esto es, agregando a un ente algo nuevo que se descubre.

En conclusión, consideramos la prueba indiciaria - también conocida como prueba indirecta- como aquella que se dirige a mostrar la certeza de un(os) hecho(s) (indicios), explicitando a través del razonamiento basado en un nexo causal y lógico entre los hechos probados y los que se trata de probar, debiendo estos estar relacionados directamente con el hecho delictivo, existiendo una coherencia y concomitancia que descarte la presencia de los llamados contraindicios (Rosas 2004: 290-291).

La doctrina considera que los indicios, en términos autónomos, son estimados sin lugar a dudas como «medios de prueba», solo que no son representativos, ni muestran directamente el hecho, solo lo indican (Montero Aroca citado en Miranda 2012: 34). Es preciso señalar que en las actividades relacionadas con el delito de corrupción de funcionarios, el conocimiento de los hechos ilícitos investigados - en su gran mayoría - no se logra a través de los medios de prueba que los puedan constatar, sino indirectamente, mediante la prueba de determinados hechos que no están constituidos por la representación de estos (Echandía citado en Kielmanovich 1996), y a partir de los cuales se les induce mediante un argumento probatorio (Lamas Puccio 2017). 


\subsection{Importancia de La prueba indiciaria}

Se entiende como prueba por indicios aquella que se dirige a convencer al órgano judicial de la verdad o certeza de hechos que no constituyen hipótesis de incriminación, pero que en atención a leyes científicas, reglas de la lógica o máximas de la experiencia, permiten tenerla razonablemente por cierta (García 2011:33).

El análisis fenomenológico en la valoración de la prueba indiciaria permite advertir que, antes de la imposición de una sanción de connotación penal, se requiere de un juicio previo en el que se declare la culpabilidad del procesado por un hecho penalmente relevante. Sucede, sin embargo, que no siempre se cuenta con prueba «directa» previa a la imposición de dicha sanción, en especial cuando de investigar datos relacionados con el delito de corrupción de funcionarios se trata, pues a la actividad procesal dirigida a formar convicción en el juez respecto a los hechos penalmente relevantes se le conoce doctrinariamente como prueba o elemento probatorio.

Es importante precisar que, en el proceso penal, la prueba es apreciada por el juzgador atendiendo a la sana crítica racional, es decir, según su libre albedrío (artículo 158.1 del Código Procesal Penal), lo que de modo alguno debe ser confundido con «discrecionalidad» $\mathrm{o}$ «arbitrariedad». En ese orden de ideas, el juez debe exponer cuál es la actividad probatoria que se ha desarrollado en el juicio, y cómo esta prueba conduce razonablemente a tener acreditado el hecho que califica como delito y los aspectos que sustentan la responsabilidad penal del procesado (Sánchez 2009: 270) ${ }^{3}$.

En esa línea de razonamiento es preciso indicar que para que el juez llegue a la certeza respecto a la responsabilidad penal del procesado en los hechos investigados, no solo es exigible la presencia de pruebas directas que vinculen al imputado con el delito, sino,

3 Aporte importante sobre el deber de motivar la valoración de la prueba. 
además, que la condena o sanción penal que se va a imponer puede ser el resultado de la valoración efectuada a una prueba indirecta o indiciaria, que una vez corroborada con otros elementos de convicción de carácter periférico sustenten su imposición.

\subsection{Aplicación de la prueba por indicios}

Según Trazegnies (2010), la prueba indiciaria es, ante todo, una verdadera prueba, esto significa que sus resultados no solo deben ser admitidos como válidos por el derecho, sino - y como condición para lo primero - que es necesario que tenga las características de seriedad, rigor, consistencia, que toda prueba debe tener si se quiere que sea utilizada. Mientras que para Perelman y OlbrechtsTyteca:

La prueba indiciaria exige que se proceda a varias selecciones de elementos indispensables para que funcione: selección de datos que se consideran relevantes, selección de hipótesis, selección de teorías que se piensa que deben ser confrontadas con los hechos, selección de los elementos mismos que constituyen los hechos. Cada una de estas selecciones implica decidir a su vez sobre criterios para hacer la selección. En consecuencia, la construcción de la certeza final está basada en múltiples elementos subjetivos o cuando menos altamente controvertibles (1970: 25).

Es evidente que la prueba indiciaria es sumamente importante en el proceso penal, y de modo más específico cuando se investigan delitos cometidos por funcionarios públicos, puesto que, atendiendo a su naturaleza, es posible alcanzar la verdad objetiva, que permitirá pasar más allá de toda duda razonable, salvaguardando en todo momento, claro está, el derecho constitucional a la presunción de inocencia. El término "más allá de toda duda razonable» no se encuentra expresamente establecido en nuestro ordenamiento; sin embargo, podemos hacer uso, si se desea, del control convencional 
bajo el tenor del artículo $66 .^{\circ}$ del Estatuto de Roma (del cual somos parte desde el 7 de diciembre de 2000), el cual establece que «Para dictar sentencia condenatoria, la Corte deberá estar convencida de la culpabilidad del acusado, más allá de toda duda razonable» (Cusi 2016: 225).

Qué duda cabe, al ser un término exclusivo del ámbito penal, la prueba indiciaria tiene la capacidad de fundar una sentencia condenatoria, pero en estricta observancia de ciertas reglas exhaustivas y concretas, a fin de no vulnerar la libertad, pues la prueba indiciaria no es una prueba residual. En ese sentido, la prueba indiciaria es aquella que se dirige a demostrar la certeza de los hechos (indicios) que no son constitutivos del delito objeto de acusación, pero a través de la lógica y de las reglas de la experiencia se puede inferir la comisión de los hechos delictivos y la participación del presunto autor (Neyra 2010: 549).

\subsection{La valoración de la prueba indiciaria en los delitos de corrupción de funcionarios}

Es claro que los operadores de justicia, y más específicamente los magistrados del Poder Judicial, al emitir pronunciamiento - con mayor énfasis en aquellos casos relacionados con delitos de corrupción de funcionarios - están obligados a significar garantía de democracia para la ciudadanía. Por ello es exigible que los indicios estén debidamente probados, ya que dependiendo de la fuerza acreditativa de aquellos el juzgador estará en la posibilidad de imponer una sentencia condenatoria al procesado.

El capítulo II del Código Penal regula los delitos cometidos por funcionarios públicos, en tanto que en la sección IV se encuentra tipificado el delito de «corrupción de funcionarios». Este último, en sus diversas modalidades, prevé como elemento común la violación de sus obligaciones funcionales, mediante un hacer o dejar de hacer. Por la diversidad de modalidades de los actos de corrupción, donde 
muchas veces no hay testigos y tampoco evidencias directas de su comisión, se complica y dificulta su probanza, pues es usual que en la práctica los elementos de prueba se encuentren en la esfera privada, esto es, dentro de la propia organización delictual. Por ese motivo, para su probanza se requiere acudir a la acreditación de otros hechos de carácter periférico o indirectos como los indicios, ya que es bastante conocido que el fundamento de todo juicio es necesariamente la prueba.

En el Nuevo Código Procesal Penal, la prueba indiciaria se encuentra regulada en el artículo 158, inciso 3, donde se precisa los requisitos exigibles para su aplicación:

a) Que el indicio esté probado. Se entiende que debe estar acreditado por medios de prueba válidos. Por ello la importancia de no confundir «indicios» con los «medios de prueba» que sirven para la comprobación de la imputación fáctica contenida en la tesis fiscal o los argumentos sostenidos por la defensa para sustentar su posición.

b) Que la inferencia esté basada en las reglas de la lógica, la ciencia o la experiencia. Lo que permite a los operadores de justicia vincular ambos presupuestos - indicios y medios de prueba- a fin de establecer entre ellos el nexo o relación de causalidad. A su vez esto sustentará la decisión emitida en un caso concreto.

c) Que cuando se trate de indicios contingentes, estos sean plurales, concordantes y convergentes, así como que no se presenten contraindicios consistentes. Este requisito de admisibilidad de la prueba por indicio le exige al juzgador observar con rigurosidad el derecho a probar o generar prueba de descargo que le asiste a los justiciables al ser garantías reconocidas constitucionalmente, por cuanto posibilita al juzgador convicción sobre la veracidad de sus argumentos. 
En la actualidad, somos testigos de que la aplicación de la prueba indiciaria está cobrando mayor realce en nuestro país, con mayor énfasis respecto a personajes que han ejercido altos cargos en el poder, quienes se encuentran en el ojo de la tormenta. Es por ello que en la aplicación de la prueba indiciaria resulta ineludible e impostergable emplear la lógica para obtener correctamente el «argumento probatorio» que se refleja en las conclusiones de las inferencias realizadas válidamente. Toda vez que la inferencia es un eslabón necesario en la dinámica cognoscitiva que se emprende partiendo del significado del indicio para descubrir aquello hacia lo que este conduce. Esta operación genera en el juez convicción o no sobre un hecho concreto.

Es importante precisar también que la prueba indiciaria se conecta de modo directo con la presunción de inocencia consagrada en la Constitución, ya que, en razón de este derecho constitucionalmente reconocido, entre la resolución de inicio de investigación (diligencias preliminares a nivel fiscal) y la ulterior resolución final que declara la culpabilidad o la inculpabilidad del procesado (sentencia), se genera un estado de sospecha que determina la necesidad del advenimiento de la actividad probatoria. Solamente a través de esta se puede acentuar o desvanecer la sospecha, pues solo al concluir la actividad probatoria se sabrá si la citada presunción es descartada o si se mantiene.

\section{LA PRUEBA INDICIARIA Y LOS DERECHOS FUNDAMENTALES}

El derecho a la prueba es un derecho fundamental de todo ser humano, dado que es inherente a la persona. Su contenido esencial es la posibilidad que tiene toda persona de utilizar los medios posibles a fin de convencer al juez sobre la verdad del interés material perseguido. Se define como aquello que tiene mérito suficiente para formar en el juez la certeza de haber alcanzado la verdad concreta a 
lo largo del desarrollo del proceso y, con ello, tener por desvirtuada la presunción de inocencia.

Es, asimismo, un instrumento que alcanza a toda persona, por lo que de manera alguna puede expandirse hasta el límite de violar los demás derechos fundamentales. Se trata de un derecho subjetivo exigible al juez, cuyo propósito es accionar la actividad probatoria en conexión con el derecho al acceso a la justicia; por ello, le está prohibido al juez utilizar directa o indirectamente las fuentes o medios de prueba obtenidos con vulneración del contenido esencial de derechos fundamentales.

El contenido esencial de los derechos fundamentales de la persona es un concepto nuevo en nuestra legislación procesal penal, pero, de primera importancia para una lectura constitucional del mismo. El contenido esencial es el núcleo duro de los derechos fundamentales, que restringe su disponibilidad frente a otros derechos fundamentales, dependiendo del caso concreto, teniendo como referencia a los principios de proporcionalidad y razonabilidad. Abad Yupanqui nos dice que: «El contenido esencial de un derecho fundamental es un "concepto jurídico indeterminado", cuyo alcance y significado no puede fijarse de manera general, sino que ha de ser precisado en relación a cada derecho fundamental» (Ugaz s. f.: 2).

El Tribunal Constitucional, respecto al debido proceso constitucional y el derecho fundamental a la prueba, establece lo siguiente:

8. [...] el derecho fundamental a la prueba tiene protección constitucional, en la medida en que se trata de un derecho comprendido en el contenido esencial del derecho al debido proceso, reconocido en el artículo 139, inciso 3, de la Constitución. Una de las garantías que asisten a las partes del proceso es la de presentar los medios probatorios necesarios que posibiliten la creación de convicción en el juzgador sobre la veracidad de sus argumentos. Sin embargo, como todo derecho fundamental, el derecho a la 
prueba también está sujeto a restricciones o limitaciones, derivadas tanto de la necesidad de que sean armonizados con otros derechos o bienes constitucionales -límites extrínsecos-, como de la propia naturaleza del derecho en cuestión -límites intrínsecos-.

9. Sin embargo, el reconocimiento del derecho a la prueba en la normatividad es restringido y se lo relaciona casi exclusivamente con la presunción de inocencia. Por eso, normalmente aparece bajo la fórmula siguiente: «la persona se considera inocente mientras no se haya declarado judicialmente su responsabilidad». Este es el enunciado utilizado en el artículo 2, inciso 24, acápite e, de la Constitución, que reproduce lo estipulado por el artículo XXVI de la Declaración Americana de los Derechos y Deberes del Hombre, $y$, en cierta forma, lo prescrito en los artículos 11, inciso 1, de la Declaración Universal de Derechos Humanos; 14, inciso 2, del Pacto Internacional de Derechos Civiles y Políticos, y 8, inciso 2, de la Convención Americana sobre Derechos Humanos.

10. No obstante, es menester considerar también que el derecho a la prueba lleva aparejada la posibilidad de postular, dentro de los límites y alcances que la Constitución y las leyes reconocen, los medios probatorios pertinentes para justificar los argumentos que el justiciable esgrime a su favor. Por ello, no se puede negar la existencia del derecho fundamental a la prueba. Constituye un derecho fundamental de los justiciables producir la prueba relacionada con los hechos que configuran su pretensión o su defensa. Según esta dimensión subjetiva del derecho a la prueba, las partes o un tercero legitimado en un proceso o procedimiento tienen el derecho de producir la prueba necesaria con la finalidad de acreditar los hechos que configuran su pretensión o defensa (Tribunal Constitucional 2007).

Queda claro que el derecho a la prueba es un derecho fundamental complejo, cuyo contenido está determinado por el derecho a ofrecer medios probatorios que se consideren necesarios, a que estos sean admitidos, adecuadamente actuados, que se asegure la producción o conservación de la prueba a partir de la actuación anticipada de 
medios probatorios y que estos sean valorados de manera adecuada y con la motivación debida, con el fin de darle el mérito probatorio que tenga en la sentencia (STC 6712-2005-HC/TC ${ }^{4}$ y STC 10142007-PHC/TC).

El principio de legitimidad de la prueba ha sido recogido por el artículo VIII.1 del título preliminar del nuevo Código Procesal Penal, que establece que todo medio de prueba solo podrá ser valorado si ha sido obtenido e incorporado al proceso por un procedimiento constitucionalmente legítimo. El Tribunal Constitucional peruano al desarrollar los alcances del derecho a la prueba, en su Sentencia n. ${ }^{\circ}$ 1014-2007-PHC/TC, considera que conforme a este derecho se exige la constitucionalidad de la actividad probatoria, que implica la proscripción de actos que violen el contenido esencial de los derechos fundamentales o transgresiones al orden jurídico en la obtención, recepción y valoración de la prueba (Talavera 2015).

\section{A MANERA DE CONCLUSIÓN}

En la actualidad, el tema en análisis está remeciendo los cimientos más importantes de nuestro sistema judicial, pues es bastante conocido que diversos pronunciamientos por la presunta comisión de delitos de corrupción de funcionarios han dado lugar a una serie de acontecimientos que vienen marcando hitos trascendentales en la historia judicial peruana.

Atendiendo al escenario en el que se desenvuelven los delitos de corrupción de funcionarios, es muy probable que no se cuente con pruebas directas, es por ello que los juzgadores deben recurrir a la

4 Exp. n. ${ }^{\circ}$ 6712-2005-HC/TC. Magaly Jesús Medina Vela y Ney Guerrero Orellana. Sentencia expedida el 17 de octubre de 2005 por el Tribunal Constitucional en sesión de Pleno Jurisdiccional, con la asistencia de los magistrados Alva Orlandini, Bardelli Lartirigoyen, Gonzales Ojeda, García Toma, Vergara Gotelli y Landa Arroyo. 
acreditación de los hechos fácticos postulados por el Ministerio Público a título de imputación penal, valiéndose de la acreditación de otros hechos de carácter periférico o indirecto, como son los indicios, para imponer sentencia condenatoria cuando se trate de sanciones penales.

La prueba indiciaria, conocida también como prueba indirecta, es la que se dirige a mostrar la certeza de hechos (indicios), explicitando a través del razonamiento basado en un nexo causal y lógico entre los hechos probados y los que se trata de probar. Estos últimos se relacionan directamente con el hecho delictivo, por lo que existe coherencia y concomitancia que descarte la presencia de los llamados contraindicios.

Los operadores de justicia, principalmente los magistrados del Poder Judicial, al emitir pronunciamiento están obligados a garantizar la democracia para la ciudadanía. Es exigible, por este motivo, que los indicios se encuentren debidamente probados, pues dependiendo de su fuerza acreditativa el juzgador estará en la posibilidad de imponer una sentencia condenatoria al procesado.

Queda claro, entonces, que la prueba indiciaria tiene estrecha relación con la presunción de inocencia que consagra nuestra Constitución Política, pues en razón de esta, entre la resolución de inicio de las investigaciones y la sentencia que concluye con la responsabilidad o no del inculpado, se genera un estado de sospecha que determina inexorablemente la necesidad del advenimiento de la actividad probatoria y solo mediante esta pueda acentuarse o desvanecerse esa sospecha.

Finalmente, se puede concluir que la prueba indiciaria o indirecta constituye una prueba en sí misma, por lo que de modo alguno podría aplicarse de manera supletoria o subsidiaria. $\mathrm{Al}$ ser la prueba indiciaria una que vale por sí misma, queda totalmente descartada la posibilidad de que en caso sea insuficiente la prueba 
material o directa se pueda recién recurrir a la prueba indirecta. No corresponde a los operadores de justicia aplicar este razonamiento al resolver procesos por corrupción de funcionarios.

\section{REFERENCIAS BIBLIOGRÁFICAS}

Cusi Rimache, Jhon Eber (2016). «Patologías de la prueba indiciaria». Actualidad Penal, 24, 224-257.

García Cavero, Percy (2011). La prueba indiciaria en el proceso penal. Lima: Ara Editores.

González Pérez, Pedro David (19 de marzo de 2016). "La corrupción en el mundo». La Prensa. Recuperado de https:// www.laprensa.com.ni/2016/03/19/opinion/2005456-lacorrupcion-en-el-mundo

Kielmanovich, Jorge (1996). Teoría de la prueba y medios probatorios. Buenos Aires: Rubinzal Culzoni.

Lamas Puccio, Luis (2017). La prueba indiciaria en el delito de lavado de activos. Lima: Instituto Pacífico.

Miranda Estrampes, Manuel (2012). La prueba en el proceso penal acusatorio. Lima: Jurista/Cedpe.

Neyra Flores, José Antonio (2010). Manual del nuevo proceso penal y de litigación oral. Lima: Idemsa.

Perelman, Chaïm y Olbrechts-Tyteca, Lucie (1970). Traité de l'argumentation. La nouvelle rhéthorique. Bruselas: Univ. Bruxelles.

Perú21 (12 de junio de 2017). «La corrupción es el principal problema del Perú, según INEI». Perú21. Recuperado de https://peru21.pe/economia/corrupcion-principal-problemaperu-inei-80745-noticia/

Poder Judicial (2013). Exp. n. ${ }^{\circ}$ 00092-2011-6-1826-JR-PE-01. Corte Superior de Justicia de Lima: 10 de junio de 2013. 
(2014). Exp. n. ${ }^{\circ}$ 0003-2013-6-1826-JR-PE-0. Corte Superior de Justicia de Lima: 17 de diciembre de 2014.

Rosas Yataco, Jorge (2004). «Prueba indiciaria: doctrina y jurisprudencia nacional». La reforma del proceso penal peruano. Anuario de Derecho Penal, 287-302.

Salas Villalobos, Sergio (2012). «El Poder Judicial peruano como objeto de estudio para la calidad de la democracia y administración de justicia en el Perú. Ventajas y dificultades». Revista Oficial del Poder Judicial, 7, 8-9, 313-334.

San Martín Castro, César (1999). Derecho procesal penal. Tomo II. Lima: Grijley.

Sánchez Velarde, Pablo (2009). "Aporte importante sobre el deber de motivar la valoración de la prueba». El nuevo proceso penal. Lima: Idemsa.

Talavera Elguera, Pablo (octubre de 2015). La prueba ilícita [diapositivas]. Recuperado de https://www.mpfn.gob.pe/ escuela/contenido/actividades/docs/4055_prueba_ilicita.pdf

Trazegnies, Fernando (2010). La teoría de la prueba indiciaria. Recuperado de http://macareo.pucp.edu.pe/ftrazeg/aafad.htm

Tribunal Constitucional (2003). Exp. n. ${ }^{\circ}$ 010-2002-AI/TC Lima. Lima: 3 de enero de 2003.

(2005a). Exp. n. ${ }^{\circ}$ 4831-2005-PHC/TC Arequipa. Lima: 8 de agosto de 2005 .

(2005b) . Exp. n. ${ }^{\circ}$ 6712-2005-HC/TC Lima. Lima: 17 de octubre de 2005.

(2007). Exp. n. ${ }^{\circ}$ 1014-2007-PHC/TC Lima. Lima: 5 de abril de 2007.

Ugaz Zegarra, Ángel (s. f.). "Algunas reflexiones en torno a la prueba ilícita». Recuperado de https://www.minjus.gob. pe/defensapublica/contenido/actividades/docs/303_9_ reflexiones_prueba_il\%C3\%ADcita.pdf 